\title{
1 The Road to the UCI: Profiling a professional Brazilian female road cycling team
}

2 Gabriel Barreto $^{1}$, Luana Farias de Oliveira $^{1}$, Tiemi Saito ${ }^{1}$, Rafael Klosterhoff ${ }^{1,2}$, Pedro Perim $^{1}$,

3 Eimear Dolan ${ }^{1}$, Rosa Maria R. Pereira ${ }^{4}$, Patrícia Campos-Ferraz ${ }^{1}$, Fernanda R. Lima ${ }^{1}$, Bryan

4 Saunders ${ }^{1,5}$

5

61 - Applied Physiology and Nutrition Research Group, School of Physical Education and

7 Sport; Rheumatology Division; Faculdade de Medicina FMUSP, Universidade de Sao Paulo,

8 Sao Paulo, SP, BR, University of São Paulo, SP, Brazil.

92 - Department of Biochemistry and Molecular Biology, Federal University of Paraná,

Curitiba, PR, Brazil.

3 - Sports Medicine Group, Rheumatology Division, Universidade de São Paulo, SP, Brazil.

4 - Bone Laboratory Metabolism, Rheumatology Division, Hospital das Clínicas HCFMUSP, Faculdade de Medicina da Universidade de Sao Paulo, SP, Brazil.

5 - Institute of Orthopaedics and Traumatology, Faculty of Medicine FMUSP, University of São Paulo, Brazil.

\section{Correspondence:}

Dr Bryan Saunders

Applied Physiology \& Nutrition Research Group,

Rheumatology Division, Faculty of Medicine FMUSP,

University of São Paulo,

São Paulo, SP, Brazil.

E-mail: drbryansaunders@ outlook.com

Phone: +55 $113061-8789$

Fax: +55 $113813-5921$

All authors have read and approved this version of the manuscript for pre-print.

Gabriel Barreto (@nutrigabarreto), Bryan Saunders (@Bicycle_Bryan), Eimear Dolan (@eimeardol)

Please cite as: Barreto, G, Oliveira, L.F., Saito, T., Klosterhoff, R., Perim, P., Dolan, E., Pereira, R. M. R., Campos-Ferraz, P., Lima, F. R., Saunders, B. (2020). The Road to the UCI: Profiling a professional Brazilian female road cycling team. Sportrxiv. doi: 10.31236/osf.io/wnpjk 


\section{Abstract}

Women's professional cycling has grown exponentially in popularity in the past years and it has been no different in Brazil. In 2019 the first Brazilian female cycling team achieved UCI ranking status. Nonetheless, there is a paucity of data regarding the seasonal demands that these athletes encounter. This semi-observational study monitored 5 athletes from a Brazilian professional female cycling team throughout their 2018 season, obtaining training and competition data, laboratory-based physiological and performance measures, and clinical and nutritional analyses. Total distance covered over the year was $11124 \pm 2895 \mathrm{~km}$ (range: 7382 to $14698 \mathrm{~km}$ ). The athletes competed in 58 races across 5 countries and 3 out of the 5 athletes sustained injuries at different moments throughout the season. Maximal oxygen uptake was reduced over the season $(\mathrm{P}=0.005)$, but Wingate and 4-km time-trial performance was unaltered (all $\mathrm{P}>0.05$ ). All athletes were healthy at the start of the season as demonstrated by the clinical analyses, while all reported regular menstrual cycles; three of the five athletes were taking oral contraceptives. Immunological and haematological parameters were maintained throughout the season and there were few reported cases of infection. Nutritional and stress markers remained largely unchanged throughout the season, although testosterone levels were low for some at various moments. Mean estimated energy availability (EEA) ranged from 32.3 to $56.8 \mathrm{kcal} \cdot \mathrm{kgLBM}^{-1} \cdot \mathrm{day}^{-1}$ during training and from 26.4 to $53.8 \mathrm{kcal} \cdot \mathrm{kgLBM}^{-1} \cdot \mathrm{day}^{-1} \mathrm{during}$ competition. The percent of training spent in optimal EEA was generally low, with three athletes spending less than $35 \%$ within the optimal intake. Bone mineral density total body Zscores ranged from -0.6 to 0.5 . Training and competition schedules of these professional Brazilian female cyclists were like those of female World Tour cyclists. Reduced exercise capacity towards the end of the season may be indicative of a gruelling year-long schedule and several of the athletes may have been exposed to sub-optimal energy availability during the season, potentially affecting testosterone levels in several athletes. No further alterations in the hormonal profile, menstrual cycle or incidences of infection were shown. These data demonstrate the complexity of professional female cycling and further longitudinal studies on top-level female cyclists are warranted. 


\section{Introduction}

Professional women's road cycling is growing in popularity and increasing in terms of numbers of participants and competitions, and in 2016 the Women's World Tour was established. In 2019, the UCI (Union Cycliste Internationale) tour calendar for the Women's World Tour comprised 23 events in ten countries across three continents, incorporating 52 days of racing (Source: www.UCI.org). In 2020, there will be a restructuring leading to four event divisions and even more races while a minimum salary cap will be introduced as well as several other positive changes, highlighting this growing sporting market. Research into elite female cycling is also growing, with recent data showing that female World Tour cyclists have up to 65 competition days, and cover between 13000 and $18000 \mathrm{~km}$ on the bike when combining training and competition each year [1].

Intense athletic calendars such as these require careful periodization of both training and nutrition practices, to ensure optimal performance and health throughout the season. Energy availability (EA) refers to the amount of energy available for basic physiological processes (such as growth, reproductive function and bone metabolism), once the demands of training have been met [2]. Normal healthy functioning of these basic physiological processes is suggested to occur with an EA of $45 \mathrm{kcal} \cdot \mathrm{kgLBM}^{-1} \cdot$ day $^{-1}$. Low EA, often defined as <30 $\mathrm{kcal} \cdot \mathrm{kgLBM}^{-1} \cdot \mathrm{day}^{-1}$, can lead to a wide range of detrimental and interrelated physiological and performance consequences (as described in the Relative Energy Deficiency in Sport [RED-S] model [3]) with menstrual dysfunction and compromised bone health [4] in particular known to be affected. Female cyclists may be at particular risk for long-term low EA $[5 ; 6]$ and, as such, adequate energy (and nutrient) intake is essential to protect the health and performance of top-level female cyclists.

Cycling is becoming increasingly popular in Brazil with the Brazilian Cycling Confederation calendar containing 44 elite female events consisting of 59 days of competition in 2019, while there are numerous other regional elite competitions. In July 2019, the first female Brazilian team gained UCI professional ranking status, highlighting the development of Brazilian cycling on the international stage. Despite a growing competitive calendar, no data exists on the typical seasonal schedule of elite Brazilian female cyclists. It is unknown whether these are similar to those of World Tour riders, whether nutritional intake is adequate for these demands and if there are any incidences of symptoms related to RED-S. Therefore, the aim of this observational investigation was to monitor the training and competition demands, nutritional 
92 habits and clinical health of a Brazilian professional female cycling team throughout a 93 competitive season. 


\section{Methods:}

\section{Participants}

Five Brazilian female cyclists (age $26 \pm 4$ y; body weight $53.6 \pm 4.2 \mathrm{~kg}$; height $1.64 \pm 0.05 \mathrm{~m}$ ) from the same professional cycling team volunteered and took part in this investigation which monitored them throughout their competitive season (2018). One of the athletes was the former Brazilian national time-trial champion and three were current members of the Brazilian national road-race team. Participants were informed of all protocols and any risks associated with the laboratorial tests in the study and provided written informed consent prior to participating.

\section{Experimental Design}

This was a semi-observational study in which we monitored the athletes throughout their competitive season. These data were presented at the 2019 Science and Cycling conference and published as a reduced abstract format previously $[7 ; 8]$. The athletes were requested to perform their normal training and competition routine as usual and were asked to provide as much additional information (injuries, sickness, etc) as possible. Training and competition data were collected to characterise the requirements during a season. All athletes provided access to their training and competition data which was acquired using their individually preferred GPS system (Garmin Connect, Strava, Training Peaks); power data was acquired from two athletes who used power meters (Garmin Vector, Garmin, USA). Athlete 1 registered power data for $92.9 \%$ (171/184) of her training days and 95.3\% (41/43) of her competition days while, for Athlete 4, data was available for 38.1\% (67/176) and 32.0\% (19/59) of her training and competition days. When data regarding competition was incomplete and the researchers were aware of the distance covered through one of the other athletes' data, it was manually added. The athletes also attended the laboratory three times throughout the year (March, July and December 2018) to perform a battery of exercise tests to determine various physiological and performance measures essential for cycling performance. The exercise protocols comprised an incremental cycling test until volitional exhaustion to determine maximal oxygen uptake $\left(\mathrm{VO}_{2 \max }\right)$, a 30-s Wingate test and a 4-km time-trial. Not all athlete completed all exercise tests throughout the season due to injuries and unavailability.

Dietary analysis was performed at the beginning and end of the competitive year (February and December) by a trained sport nutritionist at the request of the team coach. The nutritionist extracted information about the athletes' habitual food and supplement consumption by recall, 
and macronutrients and fibre intake were calculated using nutrition software (AVANUTRI, Brazil). Anthropometric measures were performed using a Harpenden calliper and a metric tape at 7 locations to determine percentage body fat and lean body mass. These data were used to estimate energy availability (Estimated Energy Availability [EEA] = Energy Intake Exercise Energy Expenditure, normalised to lean body mass) during training and competition days using the original Harris-Benedict equation for resting metabolic rate [9], considering an average metabolic equivalent of 7.1 METs for training and 9.8 METs for competition [10] and averaging their energy intake from the two moments of assessment since these were not significantly different. Low EEA was classified as an EA $<30 \mathrm{kcal} \cdot \mathrm{kgLBM}^{-1} \cdot \mathrm{day}^{-1}$, suboptimal EEA as between 30 and $45 \mathrm{kcal} \cdot \mathrm{kgLBM}^{-1} \cdot \mathrm{day}^{-1}$, and adequate EEA as $\geq 45$ $\mathrm{kcal} \cdot \mathrm{kgLBM}^{-1} \cdot \mathrm{day}^{-1}[11]$. Blood samples were also taken at three moments (March, July and December 2018) for determination of biomarkers indicative of clinical health.

\section{Laboratorial Procedures}

$\mathrm{VO}_{2 \max }$ test

The incremental cycling test was performed on a cycle ergometer (Lode Excalibur, Lode, Lode B.V., Groningen, Netherlands) and began with a load of $50 \mathrm{~W}$, increasing every 3 min by 25 $\mathrm{W}$ until volitional exhaustion [12]. Ventilatory and gas exchange measurements were recorded using a breath-by-breath system (Quark, Cosmed, Italy) and the highest value averaged over a 15-s period was defined as individual $\mathrm{VO}_{2 \max }$. The maximal power output achieved was calculated as the last completed stage plus the fraction of time spent in the final non-completed stage multiplied by $25 \mathrm{~W}$. Heart rate (HR) was monitored (Polar H7, Polar, USA) continuously throughout the exercise with telemetry data transmission connected to a phone app (Polar Beat). The outcome measures included absolute $\left(\mathrm{aVO}_{2 \max } ; \mathrm{L} \cdot \mathrm{min}^{-1}\right)$ and relative $\left(\mathrm{rVO}_{2 \max }\right.$; $\left.\mathrm{ml} \cdot \mathrm{kg}^{-1} \cdot \mathrm{min}^{-1}\right)$ maximal oxygen output, absolute $\left(\mathrm{aW}_{\max } ; \mathrm{W}\right)$ and relative $\left(\mathrm{rW}_{\max } ; \mathrm{W} \cdot \mathrm{kg}^{-1}\right)$ maximal power output, and ventilatory thresholds 1 (VT1; \%aW $\mathrm{axx}_{\text {ax }}$ and 2 (VT2; \%aW $\mathrm{aWx}_{\max }$.

\section{0-s cycling Wingate}

The Wingate was performed on a cycle ergometer (Lode Excalibur, Lode, Lode B.V., Groningen, Netherlands). The athletes' feet were securely attached to the pedals using toe clips and straps before they began a $10 \mathrm{~min}$ warm-up against a resistance of $1.5 \mathrm{~W} \cdot \mathrm{kg}^{-1}$, followed by $1 \mathrm{~min}$ at $75 \mathrm{~W}$. Participants were free to choose their preferred cadence during the warm-up, but were required to lower their cadence to $60 \mathrm{rev} \cdot \mathrm{min}^{-1}$ during the final $15 \mathrm{~s}$ prior to the Wingate to initiate the sprint with this rolling cadence. Participants were given a $5 \mathrm{~s}$ countdown 
prior to the sprint and were specifically instructed not to begin sprinting until specifically instructed to. The participants remained seated throughout and strong standardised verbal encouragement was given throughout. The resistance applied was $0.6 \mathrm{Nm} \cdot \mathrm{kg}^{-1} \mathrm{BM}$ and data was sampled at a rate of $5 \mathrm{~Hz}$. Absolute (aPPO; W) and relative $\left(\mathrm{rPPO} ; \mathrm{W} \cdot \mathrm{kg}^{-1}\right)$ peak power output and absolute (aMPO; W) and relative (rMPO; $\left.\mathrm{W} \cdot \mathrm{kg}^{-1}\right)$ mean power output were determined.

\section{4-km cycling time-trial}

The time-trial was performed on the athletes' individual bicycles attached to a roller connected to software (CompuTrainer, RacerMate Inc, South Dakota, USA). The bicycle was calibrated according to recommendations before participants performed a 10 min warm-up at $125 \mathrm{~W}$, followed by a 2 min rest period during which time they remained quietly seated on the bike, before performing the 4-km cycling time-trial. Participants were instructed to complete the exercise in the fastest possible time and verbal encouragement was provided throughout. The starting gear was standardised for each session, but the athletes could then change gearing throughout the time-trial as required. Participants were blinded to all performance variables except distance covered. Time to completion (TTC; s) and mean power output (MPO; W) were recorded as exercise performance measures.

\section{Other measurements}

\section{Clinical analyses}

Clinical analyses were performed at three moments throughout the year (February, July and December). Menstrual cycle health was assessed via a questionnaire. Blood samples were analysed at a central laboratory (Clinical Hospital of São Paulo) for immunological and haematological parameters (haemoglobin, haematocrit, leukocytes), nutritional status (vitamin B12, vitamin B, folic acid, total protein, albumin and ferritin) and stress markers (uric acid, creatine kinase, free and total testosterone, cortisol, thyroid-stimulating hormone). A total body scan to determine bone mineral density (BMD) was performed at the end of the season using an Dual X-ray Absorptiometry scan (DXA; Discovery A; Hologic Inc., Bedford, USA). Low BMD was defined as a $\mathrm{Z}$ score $\leq-1[3]$.

\section{Statistics}

Distance cycled and EEA data were analysed using a one-way ANOVA with competition/training as fixed factors and athletes as random factors using the software Rstudio. 
196 Tukey post-hoc comparisons were made if statistical significance had been found. Laboratory 197 parameters were analysed using a one-way mixed model considering time as a fixed factor (3 198 levels) and athletes as a random factor using SAS ${ }^{\circledR}$ University Edition. Data are presented as 199 mean \pm 1 SD. Results were interpreted according to the statistical probabilities of rejecting the 200 null hypothesis (H0) and in the following categories: $\mathrm{p}>0.1$ : no evidence against H0; $2010.05<\mathrm{p}<0.1$ : weak evidence against H0; $0.01<\mathrm{p}<0.05$ : moderate evidence against H0; $2020.001<\mathrm{p}<0.01$ : strong evidence against $\mathrm{H} 0 ; 0.01<\mathrm{p}<0.001$ : very strong evidence against $\mathrm{H} 0$ 203 [13]. Outcomes are reported as mean \pm 1SD unless otherwise stated. 
The athletes spent a total of $193 \pm 56$ days on the bike (range: $104-234$ days), completing 164 \pm 45 days training (range: $89-206$ days) and $30 \pm 16$ days competing (range: $15-55$ ). The total distance covered over the year was $11124 \pm 2895 \mathrm{~km}$, ranging between 7382 and 14698 $\mathrm{km}$ (Figure 1). Total distance covered during training was higher compared to competition (9037 \pm 2027 vs. $2111 \pm 1253 \mathrm{~km}$ ) for all athletes, as was time spent training (334 \pm 72 vs. 61 $\pm 33 \mathrm{~h}$; Figure 1). Mean distance covered during a training session was $54.9 \pm 28.4 \mathrm{~km}$ and $68.1 \pm 30.8 \mathrm{~km}$ during competition. Mean distance during competition was higher than that of training sessions $(11.5 \mathrm{~km}, 95 \% \mathrm{CI} 16.2-6.8, \mathrm{P}<0.0001)$. Mean power output during training was $112 \pm 26 \mathrm{~W}$ for Athlete 1 and $126 \pm 15 \mathrm{~W}$ for Athlete 4. During competition, mean power output was $170 \pm 32 \mathrm{~W}$ for Athlete 1 and $156 \pm 12 \mathrm{~W}$ for Athlete 4 .

The athletes competed in 58 separate races over the year across 5 countries (Brazil, Belgium, Chile, Uruguay and Italy), amassing a total of 17 gold, 12 silver and 9 bronze-placed finishes (Figure 1). Athlete 3 sustained a crash in January while competing in Uruguay and suffered a small Radius fracture. Four of the 5 athletes travelled to Belgium for a 10 -week period between April and June, competing in 19 races during this time. Athletes 1 and 2 travelled to Chile for the Pan American Track Cycling Championships in May. Athlete 2, who did not travel to Belgium, fractured her wrist prior to mid-season testing and did not take part in these evaluations. Two of the athletes were called up to represent Brazil at the 2018 UCI Road World Championships in the Women's Elite Individual Time Trial (Athlete 1) and the Elite Road Race (Athlete 4). Athlete 1 crashed during a race in early August and suffered numerous grazes which became infected and required a bout of antibiotics, as well as concussion, ruling her out of the World Championships. She then also sustained a further fall shortly following her return to training in September, fracturing her collarbone and requiring surgery. Athlete 3 became pregnant towards the end of the season and did not engage in any further training, competition or assessments.

\section{Laboratorial procedures}

Individual VO2max ranged from 51.2 to $62.3 \mathrm{ml} \cdot \mathrm{kg}^{-1} \cdot \mathrm{min}^{-1}$ at the start of the season (Table 1). There was an effect of time for $\mathrm{rVO} 2 \mathrm{max}(\mathrm{P}=0.005)$ with lower values over the season (Table 1). There was no evidence for a change in $\mathrm{rVO} 2 \mathrm{max}$ from Start to Mid $(\mathrm{P}=0.988)$ but there was strong evidence of a difference from Start to End $(\mathrm{P}=0.005)$ and Mid to End $(\mathrm{P}=0.008)$. 
The same pattern was apparent for aVO2max $(\mathrm{P}=0.005)$, aWmax $(\mathrm{P}=0.005)$ and $\mathrm{rWmax}(\mathrm{P}$ $=0.01$ ), all of which showed no evidence of any change from Start to Mid but moderate to strong evidence of a reduction from Start to End (all $\mathrm{P} \leq 0.01$ ) and Mid to End (all $\mathrm{P} \leq 0.02$ ). Performance measures during the 30-s Wingate test and the 4-km TT were unchanged throughout the season (all $\mathrm{P}>0.1$, Table 2).

\section{Body composition, nutritional intake and estimated energy availability}

Nutritional intake for all athletes is presented in Table 3. Total calorie intake ranged from 42 to $69 \mathrm{kcal} \cdot \mathrm{kg}^{-1} \mathrm{BM}$ per day, protein from 2 to $4 \mathrm{~g} \cdot \mathrm{kg}^{-1}$, carbohydrate between 4 and $9 \mathrm{~g} \cdot \mathrm{kg}^{-1}$ and fat from $1-2 \mathrm{~g} \cdot \mathrm{kg}^{-1}$. Fibre intake was lower than the daily recommended allowance $(25-30$ $\mathrm{g} \cdot \mathrm{kg}^{-1}$ ) for 3 out of 5 athletes at the start of the season and 3 out of 4 athletes at the end (Table 5). Mean estimated energy availability during competition was $35.0 \pm 14.5 \mathrm{kcal} \cdot \mathrm{kgLBM}^{-1} \cdot \mathrm{day}^{-}$ ${ }^{1}$ and 42.2 \pm 11.3 during training days (Figure 2). Overall, mean EEA values were higher during training days than competition $\left(3.8 \mathrm{kcal} \cdot \mathrm{kgLBM}^{-1} \cdot \mathrm{day}^{-1}, 95 \% \mathrm{CI} 2.3-5.2, \mathrm{p}<0.0001\right)$ although post-hoc analysis showed only athletes 1 and 4 had mean EEA values lower in competition compared to training days $\left(-7.3 \mathrm{kcal} \cdot \mathrm{kgLBM}^{-1} \cdot\right.$ day $^{-1}, 95 \% \mathrm{CI} 2.5-12.1$; and $-5.9 \mathrm{kcal} \cdot \mathrm{kgLBM}^{-}$ ${ }^{1} \cdot$ day $^{-1}, 95 \%$ CI 1.6-10.12). The percent of training spent in optimal EEA was generally low, with three athletes spending less than $35 \%$ within the optimal intake zone, and $0 \%$ of training sessions considered optimal for Athlete 4. Similarly, these same three athletes had an adequate EEA for less than $20 \%$ of their competition days, while as much as $65 \%$ of competition days were in low EEA for Athlete 4. Athlete 5 did not have low EEA for any training or competition day (Figure 3).

There was no evidence for an effect of time on body mass $(\mathrm{P}=0.20)$, body mass index $(\mathrm{P}=$ $0.25)$ or sum of skinfolds $(\mathrm{P}=0.39)$. There was no evidence for an effect of time for absolute $(\mathrm{P}=0.42)$ or relative $(\mathrm{P}=0.46)$ protein intake, absolute $(\mathrm{P}=0.41)$ or relative $(\mathrm{P}=0.23)$ carbohydrate intake, absolute $(\mathrm{P}=0.50)$ or relative $(\mathrm{P}=0.48)$ fat intake or total fibre intake $(\mathrm{P}$ $=0.98)$. There was no difference for absolute calorie intake $(\mathrm{P}=0.22)$ although relative to body mass, there was moderate evidence of a decrease from Start to End season for calorie consumption ( $\mathrm{P}=0.03$, Table 3 ). Athletes reported taking supplements daily including protein bars and whey protein, carbohydrate gels, creatine, potassium, vitamin B and C, folic acid, multi-ingredient powders, resveratrol, chelated magnesium and multivitamins.

\section{Clinical analyses}


272 All athletes were healthy at the start of the season as demonstrated by the clinical analyses 273 (Table 4). Three of the five athletes were taking oral contraceptives while the remaining two 274 reported (to the team physician) regular menstrual cycles between 21 and 35 days. 275 Immunological and haematological parameters were maintained throughout the season and the 276 only reported case of any kind of infection was from Athlete 1 who suffered a cutaneous 277 infection of her shoulder injury from a fall in August that required a round of antibiotics. 278 Nutritional and stress markers remained largely unchanged throughout the season for those 279 who repeated the exams, although testosterone levels were low for some individuals at various 280 moments (Table 4). There was a recurrent locomotor complaint of lower back pain from 3 281 athletes during the year which was treated with physical therapy in all cases.

283 Bone mineral density at the various measured sites are reported in Table 5. Total body BMD 284 was between 1.004 and $1.077 \mathrm{~g} \cdot \mathrm{cm}^{-2}$ and total body Z-scores ranged from -0.6 to 0.5 (Table 285 5). Athlete 4 did not perform the DXA scan as she was pregnant at the time. 


\section{Discussion}

287 The aim of this study was to monitor the training and competition demands, nutritional habits and clinical health of a Brazilian professional female cycling team throughout their competitive season. Our data showed that these female professional Brazilian cyclists covered similar distances during a competitive season to those of a World Tour level rider, competing in a multitude of international competitions. Several of the riders sustained injuries throughout the season, including fractures after falling in either training or competition. Endurance exercise capacity was reduced towards the end of the season, although other laboratorial exercise measures were unchanged. Several of the athletes showed sub-optimal energy availability during the season as well as low testosterone levels, although no other alterations in the hormonal profile or incidences of infection were shown.

The distances covered over the year by these professional Brazilian cyclists were similar to those of World Tour level cyclists [1], one athlete covering up to almost $15000 \mathrm{~km}$. This was performed across $\sim 150$ training days and $\sim 30$ competition days in 5 different countries. These numbers would have been higher if it was not for some of the unfortunate consequences associated with bicycle racing, namely crashes, particularly during flat stages [14]. Several of the athletes sustained fractures during competition, ruling them out for several weeks of the year, while one athlete also suffered a fractured arm outside of cycling which limited her ability to ride for a period. To obtain ranking points for the UCI ranking and to qualify for the 2020 Olympic Games, the team travelled to Belgium for 10 weeks to compete in international ranking events between April and June where they competed in 19 races (the team officially achieved UCI status in June 2019). The team also competed together in Uruguay while some of the athletes were called up to represent Brazil at the Pan American Track Cycling Championships in Chile and the 2018 UCI Road World Championships in Austria. This illustrates the complex and unpredictable nature of professional cycling which involves substantial time training, competing and travelling, as well as significant risks of injury. Another level of complexity exists for the female athlete; Athlete 3 became pregnant towards the end of the season. Current recommendations suggest that elite athletes that become pregnant should refrain from training at intensities above $90 \% \mathrm{VO}_{2 \max }[15]$ although our athlete immediately ceased training and competition and did not complete any end of season analyses. The athlete has since returned to training in the 2019 season following the birth of a healthy boy. 
All athletes had high $\mathrm{VO}_{2 \max }$ values at the start of the season, classifying them as trained, welltrained or professional according to the criteria of Decroix et al. [12]. This was maintained throughout mid-season, fluctuating by $\sim 3 \%$, but end of season testing revealed an impaired exercise capacity during the incremental cycling test. This is in contrast to previous research showing no decline in maximal oxygen uptake in professional and competitive male cyclists during a competitive season $[16 ; 17]$. Although the explanation for the decline in laboratorial test performance in these professional female cyclists is unclear, we can speculate that it may be due to a plethora of factors including minor weight gain, accumulated fatigue over the season and injuries. Specifically, Athlete 1 , whose $\mathrm{VO}_{2 \max }$ and $\mathrm{W}_{\max }$ dropped by as much as $16 \%$, suffered a number of injuries towards the end of the season, while Athlete 2, with a $17 \%$ reduction in $\mathrm{VO}_{2 \max }$, suffered a fracture in early June and only returned to training after almost two months. It must also be acknowledged that only 3 of the athletes completed the end of season testing, although all three showed substantial reductions in exercise capacity $(>6 \%)$. Despite this, performance during the 30-s Wingate test and 4-km TT performance was unchanged throughout the season, suggesting anaerobic power is more resistant than endurance exercise capacity to the fatigue associated with a competitive season. Monitoring fatigue and its foremost causes over a cycling season would allow greater understanding of the demands placed upon this athlete population and may also provide insight into optimising preparation (i.e. training, nutrition, schedule) for peak competitive performance.

Three of the athletes spent most of their training and competition days in sub-optimal EEA, with Athlete 4 performing up to $66 \%$ of her competition days in low EEA according to our estimations. Cyclists have been shown to be susceptible to low EA due to several reasons including practical difficulties of matching the energy expenditure during prolonged periods of cycling [18], while hunger may be suppressed for several hours following strenuous exercise [19]. The cyclists here reported particular difficulty in maintaining their dietary needs when traveling to foreign countries due to cultural differences in cuisine. Certainly, this is an important factor that elite cycling teams should prepare for and should consider bringing their own food wherever possible. Poor nutritional knowledge is another factor that could lead to low EA [20], although these athletes had nutritional advice from a trained sport nutritionist throughout the season. Nonetheless, two athletes reported (directly to the nutritionist) being afraid to eat carbohydrate at night for fear of gaining weight, which highlights the often-delicate balance of an elite athlete's mind frame towards nutrition for performance. This behaviour could also be classified as disordered eating, which can be defined as a lack of adjustment to 
increased physical activity [21]. Elite cyclists have been shown to be a "weight-conscious population" [22] and this professional Brazilian team appears no different. Despite no large weight fluctuations across the season, the low EEA at time points during the year may be reflected in some of the low testosterone levels which may be an attempt by the body to conserve energy. However, caution should be taken when interpreting these data since there are several issues associated with the calculation of estimated energy availability in an applied setting [20] while regular use of the contraceptive pill may also lead to low levels of testosterone [23], a potential confounding factor. Chronic low energy intake could lead into these complications, which are especially common in sports such as cycling in which lighter weight may count as a competitive advantage [24].

Evidence suggests that cyclists may be at risk for low BMD, particularly at the lumbar spine [25], due to the non-weight-bearing nature of the sport. High-volume endurance exercise might also increase calcium loss in sweat, acutely augmenting parathyroid hormone concentrations which leads to bone resorption to maintain serum calcium [26]. Low EA can also compromise bone health [4] and, since several of the athletes had sub-optimal EEA throughout the season, these athletes appear to be at particular risk. Nonetheless, none of the athletes measured had low BMD [3], although Athlete 1 was below the reference value of the population. This athlete also sustained a fracture during the year, namely a compound fracture of the clavicle (Athlete 1). This cannot be causally linked using the available data but since low-BMD is associated with fracture risk, we recommend that this athlete undergo continuous monitoring, and that strategies are implemented to protect her bone health. Previous studies have shown contradictory findings regarding BMD loss over a season, with reports of losses in BMD [27] and no change [5] in female cyclists. Unfortunately, we could only measure BMD at the end of the season, meaning we could not monitor changes over time but that is certainly an avenue of investigation that should be done since female cyclists, in particular, can be considered a high-risk group for development of low BMD.

Several of the limitations of this semi-observational study highlight the difficult and dynamic nature of data collection with elite athletes but may also reflect the state of professional cycling in Brazil. Indeed, the sample size of five athletes might be considered low, but it must be emphasized that these were all the athletes from the only elite Brazilian female cycling team at the time of data collection. Due to limited resources, we could not accompany the athletes during race days and travel and, thus, relied on self-report, distance monitoring and their use 
of technology. These limitations were highlighted when Athlete 3's GPS unit broke while away in Belgium and did not have the financial means to immediately replace it. This likely also reflects the limited investment currently associated with female cycling in Brazil. A further limitation was that we could not calculate objective measures of training or competition since the athletes did not have their own individual heart rate monitors or, if they did, rarely employed it throughout training or competition resulting in a lack of usable data. Finally, although two athletes had power meters, they seldom employed them during the season. The lack of objective training and competition data is perhaps again reflective of the lack of funding available; despite being a professional team competing internationally, they were not provided with these resources.

\section{Conclusions}

400 The training and competition schedules of these professional Brazilian female cyclists were 401 like those of female World Tour cyclists. Exercise capacity was reduced towards the end of the season, perhaps indicative of this gruelling year-long schedule. Several of the athletes may have been exposed to sub-optimal energy availability during the season and may have resulted in low testosterone levels in several athletes, although no further complications were apparent. These data demonstrate the complexity of professional female cycling and further longitudinal studies on top-level female cyclists to assess the various physiological, nutritional and performance demands throughout a season are warranted. 


\section{Acknowledgments}

409 We are grateful to all the athletes for allowing us to monitor them throughout the season and 410 for taking time out of their schedules to perform the physical tests.

411 Gabriel Barreto (2017/15314-1), Pedro Perim (2018/01594-5), Eimear Dolan (2019/05616-6) 412 and Bryan Saunders (2016/50438-0 and 2017/04973-4) have been financially supported by 413 Fundação de Amparo à Pesquisa do Estado de Sao Paulo. This study was financed in part by 414 the Coordenação de Aperfeiçoamento de Pessoal de Nível Superior - Brasil (CAPES) - Finance 415 Code 001. 
[1] D. Sanders, T. van Erp, and J.J. de Koning, Intensity and Load Characteristics of Professional Road Cycling: Differences Between Men's and Women's Races. Int J Sports Physiol Perform (2019) 1-7.

[2] A.B. Loucks, B. Kiens, and H.H. Wright, Energy availability in athletes. J Sports Sci 29 Suppl 1 (2011) S7-15.

[3] M. Mountjoy, J. Sundgot-Borgen, L. Burke, S. Carter, N. Constantini, C. Lebrun, N. Meyer, R. Sherman, K. Steffen, R. Budgett, and A. Ljungqvist, The IOC consensus statement: beyond the Female Athlete Triad--Relative Energy Deficiency in Sport (RED-S). Br J Sports Med 48 (2014) 491-7.

[4] M. Papageorgiou, E. Dolan, K.J. Elliott-Sale, and C. Sale, Reduced energy availability: implications for bone health in physically active populations. Eur J Nutr 57 (2018) 847-859.

[5] R.T. Viner, M. Harris, J.R. Berning, and N.L. Meyer, Energy Availability and Dietary Patterns of Adult Male and Female Competitive Cyclists With Lower Than Expected Bone Mineral Density. Int J Sport Nutr Exerc Metab 25 (2015) 594-602.

[6] D. Logue, S.M. Madigan, E. Delahunt, M. Heinen, S.J. Mc Donnell, and C.A. Corish, Low Energy Availability in Athletes: A Review of Prevalence, Dietary Patterns, Physiological Health, and Sports Performance. Sports Med 48 (2018) 73-96.

[7] P. Campos-Ferraz, G. Barreto, L.F.d. Oliveira, T. Saito, R. Klosterhoff, P.H.L. Perim, E. Dolan, R.M.R. Pereira, F. Lima, and B. Saunders, A year in the life of a Brazilian professional female road cycling team Part II: Nutritional and clinical outcomes. 2019 8 (2019) 4.

[8] B. Saunders, G. Barreto, L.F.d. Oliveira, T. Saito, R. Klosterhoff, P.H.L. Perim, E. Dolan, P. Campos-Ferraz, and F. Lima, A year in the life of a Brazilian professional female road cycling team Part I: Performance measures. 20198 (2019) 3.

[9] J.A. Harris, and F.G. Benedict, A Biometric Study of Human Basal Metabolism. Proceedings of the National Academy of Sciences of the United States of America 4 (1918) 370-3.

[10] M. Jette, K. Sidney, and G. Blumchen, Metabolic equivalents (METS) in exercise testing, exercise prescription, and evaluation of functional capacity. Clinical cardiology 13 (1990) 555-65.

[11] M. Mountjoy, J.K. Sundgot-Borgen, L.M. Burke, K.E. Ackerman, C. Blauwet, N. Constantini, C. Lebrun, B. Lundy, A.K. Melin, N.L. Meyer, R.T. Sherman, A.S. Tenforde, M. Klungland Torstveit, and R. Budgett, IOC consensus statement on relative energy deficiency in sport (RED-S): 2018 update. Br J Sports Med 52 (2018) 687-697.

[12] L. Decroix, K. De Pauw, C. Foster, and R. Meeusen, Guidelines to Classify Female Subject Groups in Sport-Science Research. Int J Sports Physiol Perform 11 (2016) 204-13.

[13] V. Amrhein, F. Korner-Nievergelt, and T. Roth, The earth is flat ( $p>0.05)$ : significance thresholds and the crisis of unreplicable research. PeerJ 5 (2017) e3544.

[14] A. Lucia, J. Hoyos, and J.L. Chicharro, Physiology of professional road cycling. Sports Med 31 (2001) 325-37.

[15] K. Bo, R. Artal, R. Barakat, W.J. Brown, G.A.L. Davies, M. Dooley, K.R. Evenson, L.A.H. Haakstad, B. Kayser, T.I. Kinnunen, K. Larsen, M.F. Mottola, I. Nygaard, M. van Poppel, B. Stuge, and K.M. Khan, Exercise and pregnancy in recreational and elite athletes: 2016/2017 evidence summary from the IOC expert group meeting, 
Lausanne. Part 5. Recommendations for health professionals and active women. Br J Sports Med 52 (2018) 1080-1085.

[16] J. Hopker, D. Coleman, and L. Passfield, Changes in cycling efficiency during a competitive season. Med Sci Sports Exerc 41 (2009) 912-9.

[17] A. Lucia, J. Hoyos, J. Pardo, and J.L. Chicharro, Metabolic and neuromuscular adaptations to endurance training in professional cyclists: a longitudinal study. The Japanese journal of physiology 50 (2000) 381-8.

[18] W.H. Saris, M.A. van Erp-Baart, F. Brouns, K.R. Westerterp, and F. ten Hoor, Study on food intake and energy expenditure during extreme sustained exercise: the Tour de France. International journal of sports medicine 10 Suppl 1 (1989) S26-31.

[19] J. Dorling, D.R. Broom, S.F. Burns, D.J. Clayton, K. Deighton, L.J. James, J.A. King, M. Miyashita, A.E. Thackray, R.L. Batterham, and D.J. Stensel, Acute and Chronic Effects of Exercise on Appetite, Energy Intake, and Appetite-Related Hormones: The Modulating Effect of Adiposity, Sex, and Habitual Physical Activity. Nutrients 10 (2018).

[20] L.M. Burke, B. Lundy, I.L. Fahrenholtz, and A.K. Melin, Pitfalls of Conducting and Interpreting Estimates of Energy Availability in Free-Living Athletes. Int J Sport Nutr Exerc Metab 28 (2018) 350-363.

[21] M.W. Valliant, The female athlete triad and relative energy deficiency in sport: knowledge of both can improve the health of female athletes. Strength \& Conditioning Journal 38 (2016) 35-39.

[22] E.C. Haakonssen, D.T. Martin, D.G. Jenkins, and L.M. Burke, Race weight: perceptions of elite female road cyclists. Int J Sports Physiol Perform 10 (2015) 311-7.

[23] Y. Zimmerman, M.J. Eijkemans, H.J. Coelingh Bennink, M.A. Blankenstein, and B.C. Fauser, The effect of combined oral contraception on testosterone levels in healthy women: a systematic review and meta-analysis. Human reproduction update 20 (2014) 76-105.

[24] O. Klomsten Andersen, B. Clarsen, I. Garthe, M. Morland, and T. Stensrud, Bone health in elite Norwegian endurance cyclists and runners: a cross-sectional study. BMJ open sport \& exercise medicine 4 (2018) e000449.

[25] H. Olmedillas, A. Gonzalez-Aguero, L.A. Moreno, J.A. Casajus, and G. VicenteRodriguez, Cycling and bone health: a systematic review. BMC medicine 10 (2012) 168.

[26] D.W. Barry, K.C. Hansen, R.E. van Pelt, M. Witten, P. Wolfe, and W.M. Kohrt, Acute calcium ingestion attenuates exercise-induced disruption of calcium homeostasis. Med Sci Sports Exerc 43 (2011) 617-23.

[27] V.D. Sherk, D.W. Barry, K.L. Villalon, K.C. Hansen, P. Wolfe, and W.M. Kohrt, Bone loss over 1 year of training and competition in female cyclists. Clinical journal of sport medicine : official journal of the Canadian Academy of Sport Medicine 24 (2014) 331-6. 
Table 1. Exercise performance data from the incremental cycling test to exhaustion: Maximal oxygen uptake ( $\left.\mathrm{VO}_{2 \max }\right)$, maximal power output $\left(\mathrm{W}_{\max }\right)$ and maximal heart rate (Max $\left.\mathrm{HR}\right)$.

\begin{tabular}{|c|c|c|c|c|c|}
\hline & & & Start & Mid & End \\
\hline \multirow[t]{3}{*}{ Athlete 1} & $\mathrm{VO}_{2 \max }$ & $\mathrm{ml} \cdot \mathrm{kg}^{-1} \cdot \mathrm{min}^{-1}$ & 62.3 & 61.3 & 52.5 \\
\hline & $\mathrm{W}_{\max }$ & W & 303 & 284 & 260 \\
\hline & Max HR & beats. $\min ^{-1}$ & 194 & 193 & 191 \\
\hline \multirow[t]{3}{*}{ Athlete 2} & $\mathrm{VO}_{2 \max }$ & $\mathrm{ml} \cdot \mathrm{kg}^{-1} \cdot \mathrm{min}^{-1}$ & 53.7 & - & 44.4 \\
\hline & $\mathrm{W}_{\max }$ & W & 214 & - & 184 \\
\hline & Max HR & beats. $\min ^{-1}$ & 187 & - & 184 \\
\hline \multirow[t]{3}{*}{ Athlete 3} & $\mathrm{VO}_{2 \max }$ & $\mathrm{ml} \cdot \mathrm{kg}^{-1} \cdot \mathrm{min}^{-1}$ & 51.2 & 50.3 & - \\
\hline & $\mathrm{W}_{\max }$ & W & 237 & 230 & - \\
\hline & Max HR & beats. $\min ^{-1}$ & 187 & 183 & - \\
\hline \multirow[t]{3}{*}{ Athlete 4} & $\mathrm{VO}_{2 \max }$ & $\mathrm{ml} \cdot \mathrm{kg}^{-1} \cdot \mathrm{min}^{-1}$ & 54.3 & 56.0 & 50.9 \\
\hline & $\mathrm{W}_{\max }$ & W & 252 & 255 & 240 \\
\hline & Max HR & beats. $\min ^{-1}$ & 186 & 183 & 183 \\
\hline \multirow[t]{3}{*}{ Athlete 5} & $\mathrm{VO}_{2 \max }$ & $\mathrm{ml} \cdot \mathrm{kg}^{-1} \cdot \mathrm{min}^{-1}$ & 55.9 & 56.2 & - \\
\hline & $\mathrm{W}_{\max }$ & W & 238 & 227 & - \\
\hline & Max HR & beats. $\min ^{-1}$ & 187 & 176 & - \\
\hline
\end{tabular}


510 Table 2. Exercise performance data from the Wingate test and the $4 \mathrm{~km}$ time-trial. TT, Time-trial; $\mathrm{W}$,

511 watts; s, seconds; MPO, Mean Power Output; PPO, Peak Power Output.

\begin{tabular}{|c|c|c|c|c|c|c|}
\hline & & \multirow{3}{*}{$\begin{array}{l}\text { Time } \\
\text { MPO }\end{array}$} & \multirow[b]{3}{*}{ W } & \multirow{2}{*}{$\frac{\text { Start }}{381}$} & \multirow{2}{*}{$\frac{\text { Mid }}{390}$} & \multirow{2}{*}{$\begin{array}{c}\text { End } \\
417\end{array}$} \\
\hline \multirow{6}{*}{ Athlete 1} & \multirow{2}{*}{$4 \mathrm{~km} \mathrm{TT}$} & & & & & \\
\hline & & & & 284 & 259 & 218 \\
\hline & \multirow{4}{*}{ Wingate } & PPO total & W & 791 & 663.5 & 782.1 \\
\hline & & PPO relative & $\mathrm{W} / \mathrm{kg}$ & 13.4 & 11.2 & 12.8 \\
\hline & & MPO total & $\mathrm{W}$ & 509 & 475.1 & 463.4 \\
\hline & & MPO relative & $\mathrm{W} / \mathrm{kg}$ & 8.6 & 8.0 & 7.6 \\
\hline \multirow{6}{*}{ Athlete 2} & \multirow{2}{*}{$4 \mathrm{~km} \mathrm{TT}$} & Time & $\mathrm{s}$ & 447 & - & 435 \\
\hline & & MPO & $\mathrm{W}$ & 191 & - & 190 \\
\hline & \multirow{4}{*}{ Wingate } & PPO total & $\mathrm{W}$ & 663 & - & 767.3 \\
\hline & & PPO relative & $\mathrm{W} / \mathrm{kg}$ & 13.8125 & - & 14.9 \\
\hline & & MPO total & W & 486 & - & 494.1 \\
\hline & & MPO relative & $\mathrm{W} / \mathrm{kg}$ & 10.1 & - & 9.6 \\
\hline \multirow{6}{*}{ Athlete 3} & \multirow{2}{*}{$4 \mathrm{~km} \mathrm{TT}$} & Time & $\mathrm{s}$ & 408 & 409 & - \\
\hline & & MPO & W & 226 & 224 & - \\
\hline & \multirow{4}{*}{ Wingate } & PPO total & $\mathrm{W}$ & 760 & 729.4 & - \\
\hline & & PPO relative & $\mathrm{W} / \mathrm{kg}$ & 13.6 & 13.1 & - \\
\hline & & MPO total & W & 466 & 457.3 & - \\
\hline & & MPO relative & $\mathrm{W} / \mathrm{kg}$ & 8.3 & 8.2 & - \\
\hline \multirow{6}{*}{ Athlete 4} & \multirow{2}{*}{$4 \mathrm{~km} \mathrm{TT}$} & Time & $\mathrm{s}$ & 413 & 409 & 410 \\
\hline & & MPO & $\mathrm{W}$ & 219 & 221 & 222 \\
\hline & \multirow{4}{*}{ Wingate } & PPO total & $\mathrm{W}$ & 692 & 671.3 & 731.7 \\
\hline & & PPO relative & $\mathrm{W} / \mathrm{kg}$ & 13.1 & 12.7 & 13.4 \\
\hline & & MPO total & $\mathrm{W}$ & 495 & 477.6 & 499.8 \\
\hline & & MPO relative & $\mathrm{W} / \mathrm{kg}$ & 9.3 & 9.0 & 9.2 \\
\hline \multirow{6}{*}{ Athlete 5} & \multirow{2}{*}{$4 \mathrm{~km} \mathrm{TT}$} & Time & $\mathrm{s}$ & - & - & - \\
\hline & & MPO & $\mathrm{W}$ & - & - & - \\
\hline & \multirow{4}{*}{ Wingate } & PPO total & W & - & 627.8 & - \\
\hline & & PPO relative & $\mathrm{W} / \mathrm{kg}$ & - & 11.9 & - \\
\hline & & MPO total & W & - & 450.2 & - \\
\hline & & MPO relative & $\mathrm{W} / \mathrm{kg}$ & - & 8.5 & - \\
\hline
\end{tabular}


Table 3. Dietary intake and anthropometric of the athletes at the start and end of the season.

\begin{tabular}{|c|c|c|c|c|c|c|c|c|c|c|}
\hline & \multicolumn{2}{|c|}{ Athlete 1} & \multicolumn{2}{|c|}{ Athlete 2} & \multicolumn{2}{|c|}{ Athlete 3} & \multicolumn{2}{|c|}{ Athlete 4} & \multicolumn{2}{|c|}{ Athlete 5} \\
\hline & Start & End & Start & End & Start & End & Start & End & Start & End \\
\hline Total calories (kcal) & 2789 & 2744 & 2920 & 2910 & 2411 & - & 2385 & 2273 & 3610 & 3217 \\
\hline Total calories $(\mathrm{kcal} / \mathrm{kg})$ & 47.2 & 44.8 & 61.3 & 56.8 & 42.5 & - & 44.7 & 42.0 & 68.6 & 61.6 \\
\hline Total protein $(\mathrm{g})$ & 176 & 170 & 123 & 195 & 130 & - & 108 & 154 & 210 & 165 \\
\hline Total protein $(\mathrm{g} / \mathrm{kg})$ & 2.97 & 2.77 & 2.58 & 3.81 & 2.29 & - & 2.03 & 2.85 & 4.00 & 3.16 \\
\hline Total carbohydrate (g) & 311 & 348 & 443 & 425 & 282 & - & 340 & 212 & 499 & 456 \\
\hline Total carbohydrate $(\mathrm{g} / \mathrm{kg})$ & 5.26 & 5.68 & 9.31 & 8.30 & 4.97 & - & 6.38 & 3.93 & 9.49 & 8.70 \\
\hline Total fat $(\mathrm{g})$ & 93 & 74 & 73 & 47 & 85 & - & 66 & 90 & 86 & 81 \\
\hline Total fat $(\mathrm{g} / \mathrm{kg})$ & 1.58 & 1.21 & 1.52 & 0.93 & 1.49 & - & 1.23 & 1.67 & 1.63 & 1.55 \\
\hline Fibre $(\mathrm{g})$ & 14 & 18 & 15 & 19 & 26 & - & 9 & 12 & 32 & 23 \\
\hline Body weight $(\mathrm{kg})$ & 59.1 & 61.3 & 47.6 & 51.2 & 56.8 & - & 53.3 & 54 & 52.6 & 52.2 \\
\hline \%Body fat & 15.6 & 15.3 & 11.3 & 14.8 & 23.5 & - & 12.5 & 15.4 & 17.9 & 17.2 \\
\hline \%Lean mass & 84.3 & 84.7 & 88.7 & 85.2 & 76.5 & - & 87.5 & 85.6 & 82.0 & 82.7 \\
\hline Body Mass Index $\left(\mathrm{kg} / \mathrm{m}^{2}\right)$ & 20.2 & 21.0 & 19.2 & 20.6 & 20.9 & - & 19.1 & 19.3 & 19.9 & 19.7 \\
\hline
\end{tabular}


Table 4. Clinical analyses performed at the start, middle (Mid) and end of the season.

\begin{tabular}{|c|c|c|c|c|c|c|c|c|c|c|c|c|c|c|c|c|}
\hline \multirow[t]{2}{*}{ Laboratory Tests } & \multirow{2}{*}{$\begin{array}{l}\text { Normal } \\
\text { range }\end{array}$} & \multicolumn{3}{|c|}{ Athlete 1} & \multicolumn{3}{|c|}{ Athlete 2} & \multicolumn{3}{|c|}{ Athlete 3} & \multicolumn{3}{|c|}{ Athlete 4} & \multicolumn{3}{|c|}{ Athlete 5} \\
\hline & & Start & Mid & End & Start & Mid & End & Start & Mid & End & Start & Mid & End & Start & Mid & End \\
\hline Leukocytes $\left(\mathrm{mil} / \mathrm{mm}^{3}\right)$ & $4.00-11.00$ & 7.31 & & 4.84 & 6.45 & - & 5.53 & 3.69 & - & - & 5.41 & - & 5.4 & 8.24 & - & - \\
\hline Haemoglobin (g/dl) & $12.0-16.0$ & 13.4 & 14.5 & 13.8 & 13.7 & 12.7 & 13.0 & 12.2 & 14.1 & - & 12.5 & 12.3 & 12.1 & 13.5 & 13.2 & - \\
\hline Haematocrit $(\%)$ & $35.0-47.0$ & 40.5 & 42.9 & 41.2 & 43.3 & 38 & 39.4 & 35.7 & 41.5 & - & 37.9 & 36.4 & 36.1 & 40.3 & 40.1 & - \\
\hline Vitamin D (ng/mL) & $30-100$ & 45.7 & 36.9 & - & 41.9 & 29.8 & - & 24.1 & 19 & - & 48.6 & 38.6 & - & 38.4 & 38 & - \\
\hline Vitamin B12 (pg/mL) & $197-771$ & 799 & 931 & 716 & 463 & 433 & 790 & 605 & 701 & - & 1010 & 1212 & 814 & 1204 & 1494 & - \\
\hline Folic Acid (ng/mL) & $3.1-17.5$ & 10.9 & 17.9 & 13.9 & 11.1 & 9.2 & 18.0 & 13.8 & 11.6 & - & 26.4 & 11.9 & 10.3 & 15.3 & 18.9 & - \\
\hline Ferritin (ng/mL) & $13-150$ & 268 & 259 & 201 & 73 & 46 & 52 & 124 & 87 & - & 431 & 385 & 356 & 154 & 149 & - \\
\hline Total Protein $(\mathrm{g} / \mathrm{dL})$ & $6.0-8.0$ & 6.9 & - & - & 7.4 & - & - & 7.0 & - & - & 7.4 & - & - & 6.7 & 6.95 & - \\
\hline Albumin (g/dL) & $3.2-5.0$ & 3.8 & - & - & 3.6 & - & - & 3.9 & - & - & 3.9 & - & - & 3.7 & 4.51 & - \\
\hline Cortisol $(\mu \mathrm{g} / \mathrm{dL})$ & $6.7-22.6$ & 11.4 & 15 & 20.8 & 17.7 & 25.9 & 26.0 & 7.7 & 12.8 & - & 13.1 & 13.3 & 20.7 & 6.1 & 9.7 & - \\
\hline Creatine kinase (U/L) & $<167$ & 153 & 310 & 123 & 86 & 83 & 89 & 77 & - & - & 142 & 558 & 133 & 95 & 127 & - \\
\hline Uric Acid (mg/dL) & $2.4-5.7$ & - & 2.5 & - & 2.7 & 2.5 & 3.6 & 3.6 & 3.7 & - & 3.7 & 3.5 & 2.5 & 2.9 & 3.5 & - \\
\hline Free Testosterone (pmol/L) & $2.4-37.0$ & 1 & 3 & 1 & 2 & 1 & 2 & 7 & 12 & - & 1 & 8 & 4 & 5 & 2 & - \\
\hline Total Testosterone (ng/dL) & $<48$ & $<12$ & 16 & $<12$ & $<12$ & $<12$ & $<12$ & 19 & 28 & - & $<12$ & 24 & 24 & 18 & $<12$ & - \\
\hline $\begin{array}{c}\text { Thyroid-stimulating } \\
\text { hormone }(\mathrm{mU} / \mathrm{L})\end{array}$ & $0.4-4.0$ & 0.92 & 1.40 & 2.46 & 4.63 & 5.96 & 7.32 & 2.96 & 3.04 & - & 3.45 & 1.87 & 3.98 & 1.72 & 2.65 & - \\
\hline
\end{tabular}


Table 5. Bone mineral density (BMD) at lumbar spine and total body, and Z-scores of total body .

\begin{tabular}{c|cccccccccc}
\hline \multicolumn{7}{c}{$\begin{array}{c}\text { BMD } \\
\left(\mathrm{g} / \mathrm{cm}^{2}\right)\end{array}$} & Z-score \\
\cline { 5 - 7 } & Head & Arms & Legs & Trunk & Ribs & Pelvis & $\begin{array}{c}\text { Total lumbar } \\
\text { spine }\end{array}$ & $\begin{array}{c}\text { Total } \\
\text { body }\end{array}$ & $\begin{array}{c}\text { Total } \\
\text { body }\end{array}$ \\
\hline $\begin{array}{c}\text { Athlete } \\
1\end{array}$ & 2.212 & 0.565 & 1.064 & 0.826 & 0.732 & 0.899 & 0.831 & 1.004 & -0.6 \\
$\begin{array}{c}\text { Athlete } \\
2\end{array}$ & 2.075 & 0.620 & 1.071 & 0.854 & 0.743 & 0.943 & 0.870 & 1.021 & 0.0 \\
$\begin{array}{c}\text { Athlete } \\
3\end{array}$ & - & - & - & - & - & - & - & - & - \\
$\begin{array}{c}\text { Athlete } \\
4\end{array}$ & 2.461 & 0.672 & 1.066 & 0.860 & 0.774 & 0.878 & 0.944 & 1.055 & 0.2 \\
$\begin{array}{c}\text { Athlete } \\
5\end{array}$ & 2.240 & 0.667 & 1.123 & 0.865 & 0.737 & 0.934 & 0.926 & 1.077 & 0.5 \\
\hline
\end{tabular}


$\square$ Training $\square$ Competition
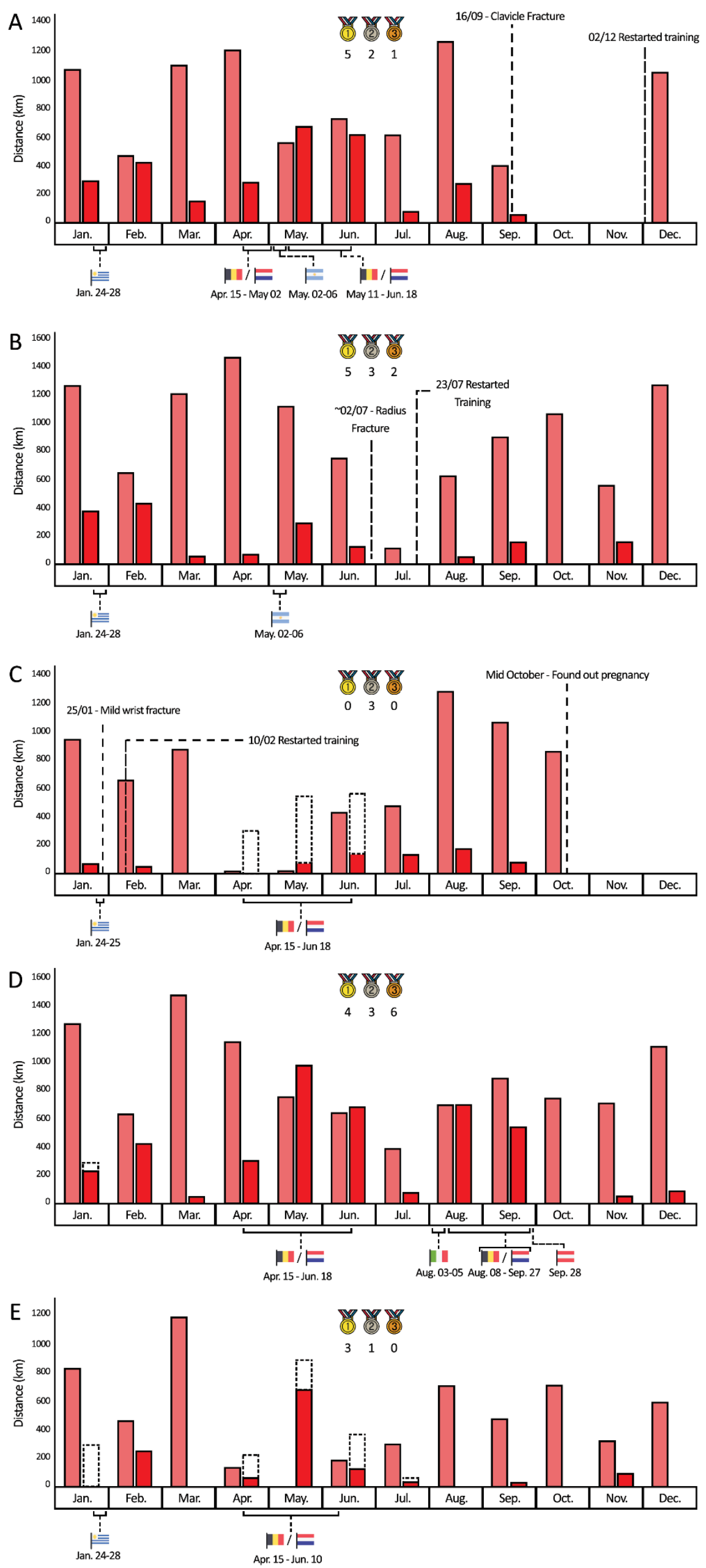
Figure 1. Cycling statistics throughout the season. A to E represents Athletes 1 to 5. 


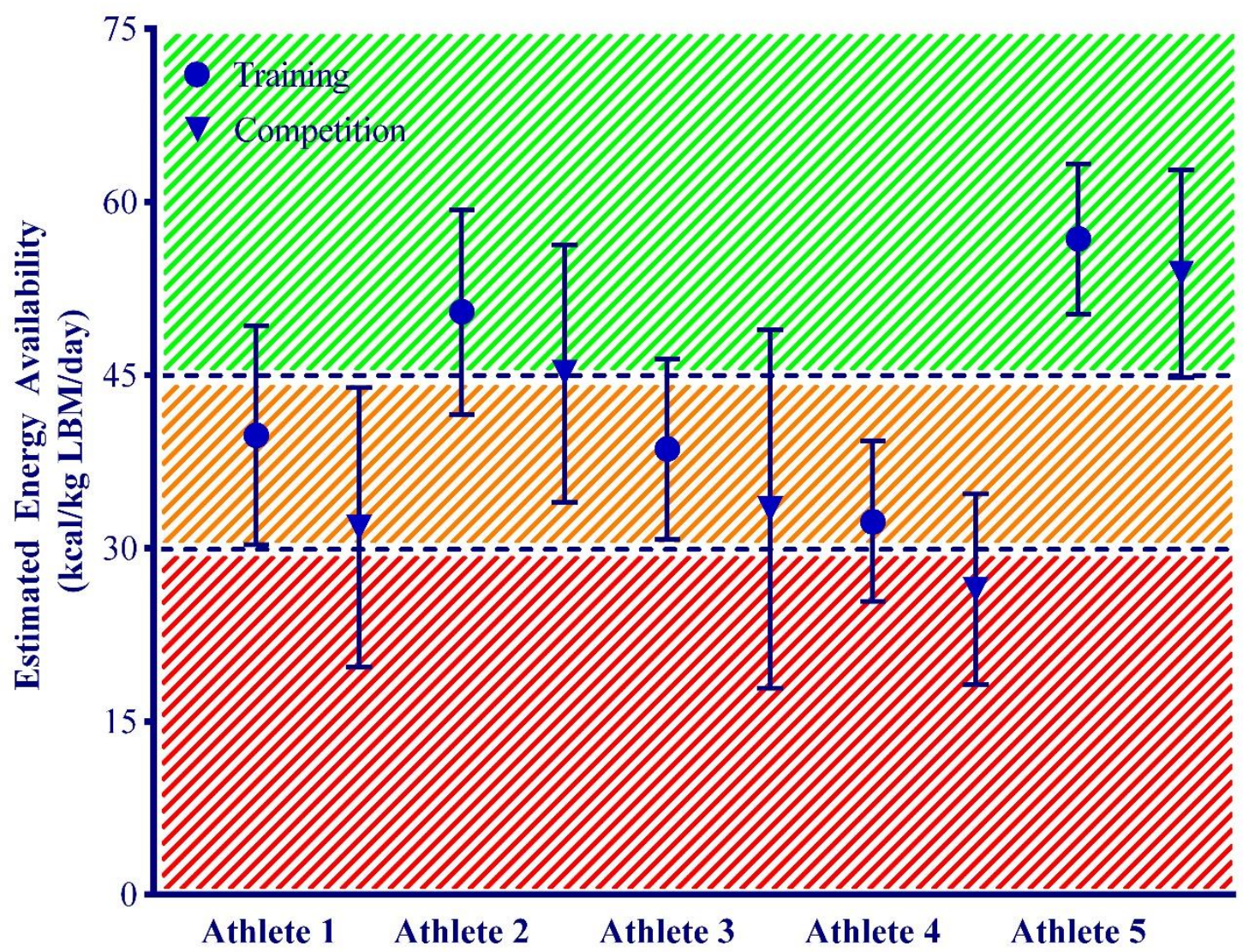

Figure 2. Mean estimated energy availability throughout the year for each athlete during training and competition. The red zone represents low energy availability, orange represents sub-optimal energy availability and green represents adequate energy availability. 
A

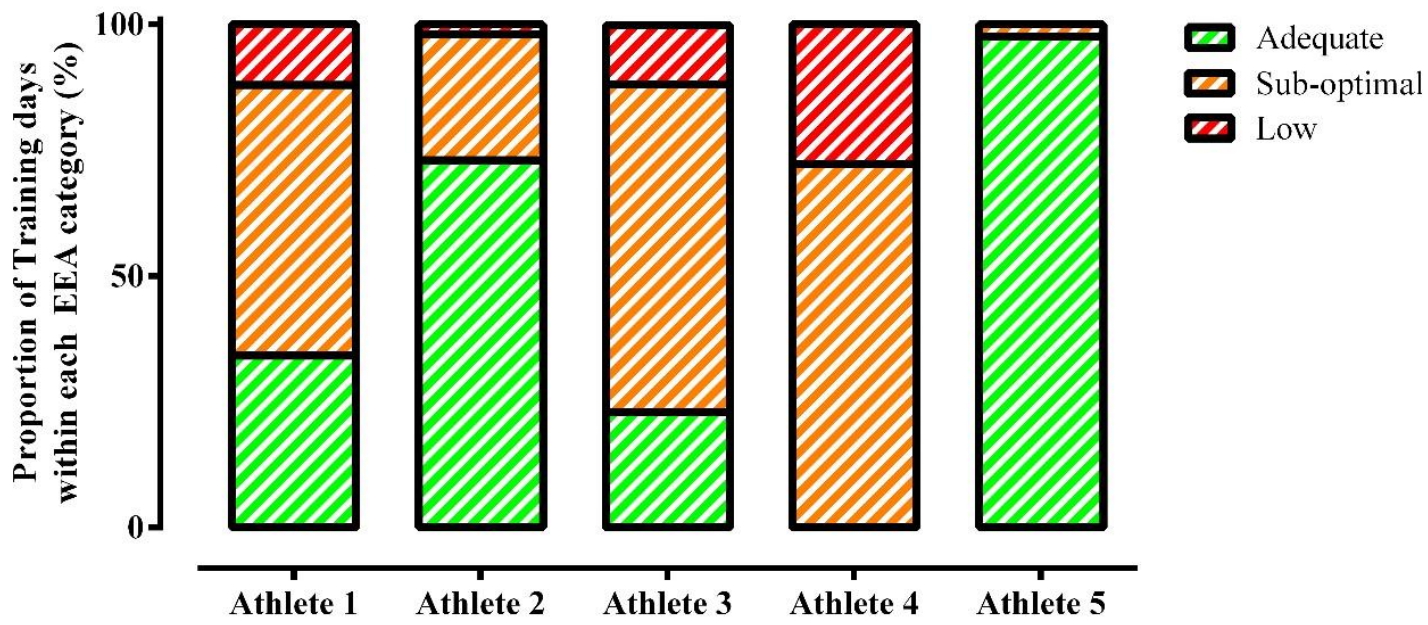

B

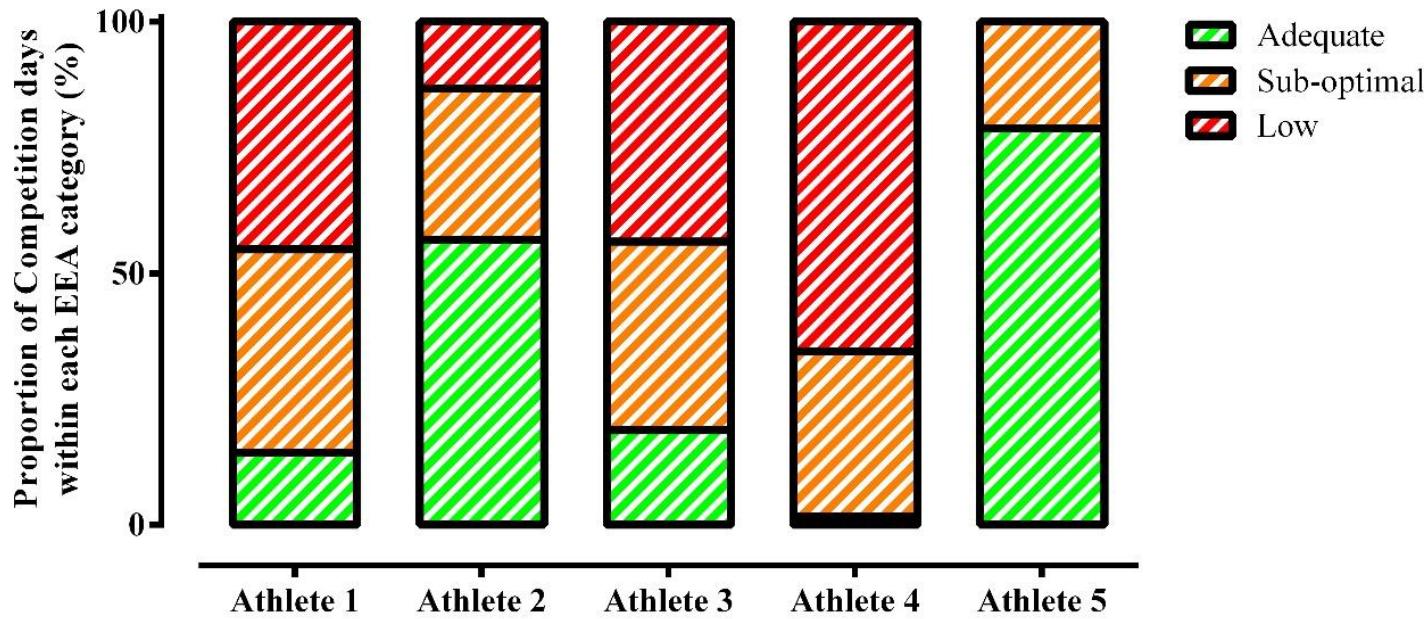

Figure 3. Proportion of training (Panel A) and competition (Panel B) spent in adequate, sub-optimal and low estimated energy availability for all the Athletes. 